\title{
Resumen / El diseñador imaginario [La creatividad en las disciplinas de diseño]
}

El Diseño reconoce un origen polémico, en tanto polemos como puesta en escena de una relación conflictiva. Es notable como las regiones del Diseño buscan recurrentemente figurativizar - esto es: crear imaginarios - su práctica a través de discursos que - en forma de manifiestos, reflexiones, ensayos, discusiones, entrevistas - una y otra vez se empeñan obstinadamente en lograr la mayor precisión en el dibujo de la profesión y sus actores - los diseñadores profesionales. Las temáticas pueden parecer múltiples, pero si se realiza un paciente proceso de deconstrucción de algunos textos veremos cómo esta figurativización se narrativiza en enunciados que dialogan entre sí, confluyendo a veces, confrontando otras, revelando la vocación de fundar el mito-imagen originario desde el cual desprender el sentido de las disciplina del diseño.

\section{Palabras clave}

Argumentación - arte - enunciado - forma - función - imagen - inmersión - narración - palabra - repliegue técnica.

\section{Summary / The imaginary designer [Creativity in design disciplines]}

Design recognizes a polemic origin; polemosas a conflict relationship. It is notable that regions of Design are products of figurativization processes - i.e. to create imaginary - of practices through discourses. Over and over again, texts are written in order to reach a more accuracy depiction of design and professional designers. Although issues discussed in this text may appear to be very varied, a patient deconstructive process can be done in order to reveal an common image among them. Texts dialog between each other - sometimes making agreements and sometimes opposing -, revealing a desire to found the original myth from which the sense of design could be grasped.

\section{Key words}

Argument - art - crease - form - function - image - immersion - narration - statement - technique - word.

\section{Resumo / 0 designer imaginário [A criatividade nas disciplinas de design]}

O Design reconhece uma origem polêmica, uma relação conflituosa. É notável como as regiões do Design procuram recorrentemente figurativizar - isto é: criar imaginários - sua prática através de discursos que - em forma de manifestos, reflexões, ensaios, discussões, entrevistas - uma e outra vez empenham-se obstinadamente em conseguir a maior precisão no desenho da profissão e seus atores: os designers profissionais. As temáticas podem parecer múltiplas, mas se realizássemos um paciente processo de desconstrução de alguns textos veremos como esse figurativismo se narra em enunciados que dialogam entre si, confluindo às vezes, confrontando outras, revelando a vocação de fundar a mito-imagem originaria desde a qual desenvolver o sentido das disciplinas do design.

\section{Palabras chave}

Argumentação - arte - enunciado - forma - função - imagem - imersão - narração - palavra - replegue técnica.

\footnotetext{
* Viviana Suárez. Arquitecta (UBA) M iembro del Comité de Arbitraje de las publicaciones del Centro de Estudios en Diseño y Comunicación de la Facultad de Diseño y Comunicación UP. Docente de la Facultad de Diseño y Comunicación UP. infocedyc@palermo.edu.ar
} 
Ponemos la palabra allí donde comienza nuestra ignorancia donde no podemos ver más allá, por ejemplo: la palabra "yo", la palabra "hacer", la palabra "sufrir", éstas son quizás las líneas del horizonte de nuestro conocimiento, pero no "verdades". Friedrich Nietzsche

\section{Y sin embargo, al principio fue el verbo}

Una forma posible de poner en marcha un discurso es siguiendo una iluminación, una intuición personal - pero a la vez colectiva -; un punto radiante que relampaguea al ser evocado por ciertas palabras. Para las profesiones proyectuales la creatividad esuna de ellas. Creatividad como concepto-objeto, centro de toda reflexión que se propone establecer umbrales que delimiten, formalicen, hagan emerger saberes y prácticas específicas que den cuenta de este sistema de disciplinas que comparten una tierra común designada como Diseño. La palabra creatividad invoca un fantasma, bajo la forma de un imaginario, que se sobreimprime a toda definición o búsqueda de significado. El fantasma ${ }^{1}$, como disparador de reflexiones, se coloca en el origen de toda actividad diferenciadora; provoca limitaciones y congregaciones en territorios comunes -puntos de vista, sistemas de creencias y de valoraciones-; lugares que, en su perspectivismo, confluyen en el trazado de modelos de comportamiento y operaciones en / sobre la realidad. En torno a este fantasma se aglutina la imagen de diseñador, en verdad creada por los deseos de figurativización de la comunidad diseñadora. Así lo especifica Silvia Fernández cuando explicita el aire de familia que une a todos quienes practican el Diseño: "Los diseñadores no tenemos en común el Diseño, lo que compartimos y nos hace semejantes, más que a otros seres de la especie, son los recursos y estrategias que movilizamos para acceder al conocimiento de la realidad y las técnicas y los procedimientos que aplicamos para modificarla." (Fernández, 2003:28)

Convoco, pues, un fantasma en forma de pregunta, interrogante que coloco en lugar del objeto de este discurso: ¿Qué es ser [un] diseñador?

Pero al ser convocado así, al formular esta pregunta de manera tan abarcadora, generalizante, -aunque habitual - el imaginario que suscita- el conjunto de imágenes que se forma en nosotros y aplicamos a un sujeto diseñador - enmascara el fantasma evocado: El infinitivo oblitera la acción y conduce la cuestión al campo de las esencias. Preguntar por el ser objetiviza al diseñador al hacerlo dependiente de la noción de diseño. A través de la cuestión del ser, el fantasma se muestra incapaz de revelar plenamente el juego de fuerzas al que está sometido, ni puede ser aprehendido como generador de las diferencias constitutivas de las disciplinas del diseño respecto del cuerpo de las profesiones liberales.

Entonces: Cambio la mirada, viro el punto de mira para problematizar el imaginario; repregunto: ¿Qué es ser diseñador para mí, para cada uno? La reformulación figurativiza, cristaliza la imagen flotante en un yo actor en un escenario de acción - el Diseño. Y como el "yo del para mí implica" -necesariamentela diferencia del para otros; figurativiza a la vez una región, un territorio compartido por un para otros en tanto iguales y delimita un afuera del para otros a quienes se dirigen las acciones del Diseño - en tanto usuarios. El para mí ubica, de esta manera, al diseñador en la red social y somete su operar dentro de un sistema de fuerzas que actúan continuamente en su identidad. Este sistema de fuerzas es quien lo lleva a repreguntarse continuamente por su identidad definida en parte por su función social, confrontada cada vez que sus productos son puestos en circulación en tanto bienes de uso.

Esta pregunta, el interrogarse sobre la identidad -quien y para quien se diseña- muestra una recurrencia abrumadora en los debates, ponencias, discursos acerca de la formación y la práctica profesional. El retorno obsesivo puede ser leído como un trabajo de construcción constante de identificación, pero también es posible accionar otra clave: La lectura de una marca de irresolución; la imposibilidad de figurar un sujeto diseñador de forma unívoca - 0 al menos territorializada -, que no presente fisuras. ¿Qué causa podría atribuirse a esta indefinición? ¿Qué justifica esta recaída constante en la búsqueda de paradigmas que sirvan para identificarnos?

Una hipótesis posible que acciona nuestro fantasma: El campo del Diseño está cruzado por fuerzas dicotómicas establecidas desde el origen mismo de la profesión. A medida que recortó sus regiones -siguiendo el modelo de parcelamiento del saber ocurrido en la cultura occidental a partir del siglo XVIII- la reflexión sobre la disciplina va trazando polarizaciones, figurativizándose en procesos que construyen paradigmas dicotómicos, los cuales, a través de la enunciación de positividades y negaciones, alcances y limitaciones, interioridades y exterioridades del campo del Diseño van trazando una axiomática que se centraliza recurrentemente en los mismos ejes: Teoría y práctica; palabra e imagen; técnica y arte. Su historia es producto de un desgajamiento del arte y una afirmación de la técnica, un desgarro que rompió la monotopía del sujeto que diseña y radicalizó los extremos. llusión, tensión hacia una monotopía en tanto único lugar posible desde el cual pensar el hacer y desde el cual actuar. Obligados a la movilidad perpetua por la constante confrontación entre los dos extremos, los discursos sobre el Diseño muestran una fuerte tendencia a crear una figura positiva, cabal, monolítica del deber ser del diseñador y su campo de acción: El diseño. Yves Zimmermann lo explicita de esta manera: "Frente al efectismo y la superficialidad que hoy caracterizan a la praxis del Diseño, es necesario definir con claridad el concepto y regresar a su esencia". (1997:33) La creatividad aparece -nuevamente- del lado de las esencias, atravesando el desgarro: "Pero después de todo, el Diseño es creatividad" (1997,11:12), sintetiza Martín Solomon. Si el Diseño puede resumirse en la creatividad, ¿Qué fenómeno de intransitividad impedirá que el diseñador sea definido esencialmente como un creativo? Tal lo esperable, el deseo del imaginario. El problema es que la creatividad tampoco es un término blanco, una palabra de significado unívoco. 
Y el problema de la identificación vuelve a complejizarse. Desmontando el concepto de creatividad, afloran a la superficie ciertos rasgos discontinuos, que -sin embargo- condensan y escenifican en sus oposiciones, el paradigma dicotómico del Diseño. En estos rasgos, en realidad, es donde el discurso encuentra el lugar para desplegar sus axiologizaciones: Un sistema de valores y disvalores que constribuyen a aspectualizar los textos, es decir, a caracterizar la figura del diseñador trazada en ellos: Su imagen ante sí mismo, su relación con la profesión, su lugar en la sociedad. El conflicto emerge en los discursos, porque ellos son superficies sobre las que trazar esencialidades, incumbencias, alcances, límites a la actividad proyectual; son lugares en los que se revelan la persistencia de esta situación desgarrada originaria en los residuos que se retienen, bajo otras apariencias, por ejemplo, la que se resume bajo la discusión entre diseñador-creador o diseñador-técnico. Los discursos funcionan como creadores de matrices y legitimadores de prácticas.

A su vez, la institucionalidad de los procesos de enseñanza-aprendizaje, propaga los modelos trazados por el entretejido de los discursos, conformando los perfiles de futuros diseñadores en el ejercicio de programas que aglutinan, sostienen y confrontan las reglas de producción de tales discursos pero que, al mismo tiempo, permiten su apropiación. Por eso, la reflexión sobre el funcionamiento y las estrategias que despliegan los enunciados sobre el perfil del diseñador en tanto función de un sujeto poseedor de un determinada habilidad o competencia - la creatividad- es sumamente revelador de la estructura que sostiene el andamiaje de la profesión.

\section{Los discursos: Construcción y justificación de la historia}

Hacer actuar los rasgos de la creatividad en los enunciados es hacer leer los textos a contrapelo para quebrar su monolitismo monológico evidenciando su interdiscursividad ${ }^{2}$ (Bajtin, 1976) -el diálogo que mantienen entre sí y con su exterior: El espacio en el cual se propagan en su apelación al otro- oyente, lector. El estar dirigido de los enunciados -su para alguien- obliga al que enuncia a la escenificación del diálogo y la asunción de un carácter conflictual, polémico que se halla en el origen de todo despliegue de persuasión: Todo discurso afirma porque contesta, interroga para ser respondido, duda para ser precisado, critica para ser definido. Todo enunciado puede resumirse como un "tomar la palabra" para construir una estrategia persuasiva que consiga traer a los otros a mi campo, sumar voluntades a nuestras causas, conformar una comunidad discursiva. La comunidad discursiva del Diseño se pone en evidencia en dos rasgos compartidos por una gran parte de los discursos; un alto grado de exposición del sujeto que enuncia y la presentación de un programa narrativo bajo la forma de razones argumentativas. Aclaremos esto; la dicotomización esencial de toda exposición de conocimiento en la cultura occidental en dos tipos de razonamiento, aparece reasumida en los enunciados sobre teorías y prácticas del Diseño. El cisma de logos y mitos separó una razón argumentativa sobre la que se construye todo pensamiento científico de una narrativa, cuyo campo quedó circunscrito a la literatura ${ }^{3}$. (Parret, 2000) La primera está orientada al mundo fenoménico y ejerce un apretado control sobre toda aparición de un sujeto-enunciador, del sujeto que habla un discurso y pone en juego un punto de vista. Desde la formulación de hipótesis hasta la demostración de tesis, todo enunciado argumentativo pretende mostrarse como la puesta en común de un saber, anclado en hechos objetivos y por lo tanto demostrables, cuya construcción obedece a la aplicación de métodos de encadenamiento según la razón lógica y que puede ser refutado. Dice Parret (2000): “La comunidad argumentativa se agrupa alrededor de la verdad de las cosas: En realidad, es una comunidad de expertos y la habilidad en el manejo de los argumentos proporciona a esta élite los privilegios de la verdad." (id:58) Esta misma pretensión de verdad es la responsable de limpiar los enunciados de cualquier marca de subjetividad: Relativismo, emotividad, valoraciones. Por otra parte, estas marcas impregnan los textos narrativos donde el yo que enuncia muestra su lugar de enunciación como un toma de posición frente al mundo. Posición que se manifiesta en su puesta en palabras de adhesiones y rechazos, adjetivaciones que implican una cadena de valoraciones, competencias del saber-hacer y del ignorar, creencia y descréditos, anclajes en el contexto del aquí y ahora. Estos tipos de texto están fuertemente orientados hacia el otro, ya que son manifestaciones de una páthica, ejercicios del deseo del enunciador, quien a través de ellos dramatiza, pone en escena los acontecimientos persiguiendo un objeto- valor. El sujeto que enuncia motoriza sus enunciados por una intencionalidad - una tensividadhacia este objeto que surge desde una carencia. Para la semiótica narratológica ${ }^{4}$, el sujeto no es sino el resultado de una competencia, de un saber hacer y sus acciones son realizadas o dificultadas por la acción de co-sujetos y anti-sujetos, por lo que todo desarrollo de una programa narrativo es básicamente conflictual.

Analicemos, entonces, una puesta en discurso del momento fundacional de las disciplinas del diseño bajo la mirada de la narratología. El texto pertenece al libro El mundo como proyecto de Otl Aicher (1994) y es particularmente iluminador en tanto puesta en mito del origen. El capítulo "La tercera modernidad" se propone rescribir -a través de la presentación de datos: Fechas, nombres y obras arquitectónicasingenieriles, todos verificables- la historia del Diseño y buscar allí su sentido fundado en lo funcional; sus esencias: Racionalidad metodológica y teleología; es decir un fin-objetivo al que se dirige la acción en oposición a los procesos de formalización vacía y a la libertad irracional del arte por el arte.

El texto se desarrolla como un recorrido, su programa narrativo pretende tender una línea que sostenga los puntos en los que se sustenta un relato-otro del 
nacimiento de la modernidad. Desde los inventos técnicos del S. XVIII a los diseños de la tercera modernidad, sumergida dentro del modernismo post-modernista. ¿Cuál es el objeto-valor del enunciado? El Diseño caracterizado por responder a fines, manejar tecnología y materiales de manera racional -constructiva-, determinar su apariencia por consecución de esos fines y no por la aplicación de repertorios formales. ¿Quiénes son los co-actores? Otros agentes de las ciencias duras o ciencias sociales, preconstituidas en el imaginario como depositarias del saber por su mayor grado relativo de estabilidad en sus respectivos campos epistemológicos y que aportan métodos y recursos racionalizadores. ¿Quienes son los anti-sujetos? El campo del arte que legitima prácticas irracionales, a las que se someten diseñadores-artistas formalizadores. Ante la creación, relacionada con la libertad absoluta del "todo-vale", las búsquedas metodológicas de control y regulación formal. Es interesante hacer notar que la denominada por Aicher (1994) primera modernidad ya presenta la radicalización dicotómica que marca todo diseño: Ingenieros técnicos versus arquitectos educados en la tradición del Beaux Arts. El texto se ideologiza rápidamente -esto es, pone en existencia los valores presentes en el paradigma axiológico, los relaciona entre sí y les asigna un lugar positivo y otro negativo que modeliza la práctica y la teoría del Diseño. El primer héroe, el ingeniero y sus modalizaciones positivas es decir la consideración de los factores económicos, el uso de la inteligencia -es decir, de la lógica frente a la emoción- el método que pregunta por la causa para regular los efectos, la consideración y atención a los datos fenoménicos de materialidad, fines, medios, todos ellos del lado de la razón práctica. La negatividad está modelizada a través de la figura del arquitecto: Es teórico, particular, parte de la visualización sin considerar la materialidad y su técnica se basa en la aplicación de un repertorio formal; es decir, opera por fuera de la realidad, aplicando la razón puramente teórica, y por lo tanto, especulativa.

"El otro fanal de la primera modernidad fue la Torre Eiffel de París, construida para la Exposición Universal de 1889, ya entonces violentamente contestada y atacada por los guardianes del arte y los valedores de la cultura. Gustave Eiffel era un ingeniero que hasta entonces había erigido atrevidos viaductos ferroviarios de construcción entramada. Estos sólo se mostraban a sí mismos como puro cálculo constructivo. Paxton construyó después como arquitecto espantosas villas neogóticas, y el propio Eiffel fue también un hombre típico de la burguesía, dividido. Por una parte ejercía su profesión de ingeniero, pero al mismo tiempo aspiraba a participar del mundo culturalmente establecido. (Aicher, 1994:41)

En el comienzo mismo del diseño arquitectónico, que se deslinda de la arquitectura entendida como un arte bello, Aicher necesita hacer la exégesis de la racionalidad que comporta el Diseño, pero a la vez marca - esto es nota como acontecimiento como dice Barthes (Barthes, 2003) - el desgarro de estar a uno u otro lado de las dos orillas que carecen de puente en la figura páthica -sufriente- de Eiffel, aun oscilando entre hombre-pragmático y hombre de cultura -léase entrada al arte.

"Las construcciones de los ingenieros del siglo XIX, las construcciones de la primera modernidad, fueron obras de técnicos; las construcciones de la segunda modernidad, en cambio, fueron obras de arquitectos. Ya la formación de unos y otros supone dos mundos diferentes. El arquitecto se forma en una institución dedicada a las artes, en una academia, en una Ecole de Beaux-Arts, en la cercanía de la escultura y la pintura. El ingeniero se forma en el ámbito de la construcción de máquinas, la estática y la cinética." (Aicher, 1994:44)

Dos modos antagónicos de concebir el mundo, dos formas contrapuestas para operar en el mundo, dos modalizaciones de sujetos diseñadores con dos competencias extremadamente polarizadas y aparentemente irreductibles.

En esta puesta en relato de la historia el paso a la segunda modernidad lejos de superar la dicotomía la agudiza, ya que el conflicto se introduce ahora en el terreno de lo social al replantear el problema en términos de forma y función:

...Ninguno de los nuevos arquitectos era técnico. Todos veían en la técnica un repertorio de formas, un dato estético conforme al inverterado proceder artístico burgués, para el que la forma es la primera causa determinante. Los ojos de un artista ven una forma, y luego éste la materializa. El espíritu es lo primero. El técnico opera de un modo completamente distinto. Tiene datos, material, medios, finalidades y condiciones económicas concretas. Contando con todo ello se pone a discurrir una forma. Esta resulta de un proceso de optimización.

La segunda modernidad fue la conquista de la técnica por el arte. El constructivista ruso no podía construir ninguna máquina. Era pintor y pintaba el mundo de las máquinas. Creaba torres y figuras de acero, silos y grúas como productos de una nueva visión estética. Se desarrollaba una revolución. La modernidad, presente ya desde hacía largo tiempo, se desplegó en una segunda vez como acontecimiento estético, como estilo, como lenguaje formal. Metódicamente se permanecía en el terreno de la Ecole de Beaux-Arts, el mundo se veía estéticamente, como forma." (id:45) El despliegue del nuevo paradigma recupera la figura de héroes mártires, lo que marca que el conflicto entre estos dos modos de operar existe en el plano epistemológico -y social- y no puede ser resuelto por el Diseño: "Hubo conflictos. Arquitectos que estaban vinculados al movimiento obrero y consideraban la arquitectura sobre todo desde puntos de vista sociales, como era el caso de Mart Stam.

El Lissitzky o Hannes Meyer, llevaron al primer plano aspectos económicos, constructivos, funcionales. Se apoyaban en los principios que regían las construcciones de los ingenieros del siglo XIX y rechazaban el papel definidor de la estética y la definición mediante conceptos formales. Pero no podían ponerse en contra de los 'pintores' que como Van Doesburg, M oholyNagy, Le Corbusier o Malevich llevaban la voz de los 
que provenían del arte. Sobre Mart Stam y Hannes Meyer se hizo un silencio que hasta hoy dura. Como oponentes a la 'arquitectura de belleza' murieron rechazados, olvidados." (id:47)

Lo que más interesa rescatar de este pasaje es la asunción de una voz acallada en la voz de quien narra: los valores positivos pertenecen a la corriente marginada de la Historia, que ha privilegiado para su modelización del diseñador, otros nombres - figuras que representaban una continuidad con aquellos paradigmas que reconfirmaban los precedentes: La arquitectura ligada al arte y no a los problemas sociales. La voz del enunciador asume un eco trágico en el "murieron rechazados, olvidados", apelando directamente al para otro del texto: Lector con quien confluir. El narrador despliega así su estrategia para reconstruir la historia de la arquitectura -en este caso el diseño arquitectónico se erige como patrón de referencia recurrente aún hoy, punto de origen de todas las disciplinas del Diseño- y convencer al lector destinatario para que co-participe en la reescritura de la historia desde una nueva puesta en valores que reordene las prioridades:

"Sin duda alguna hay fenómenos estéticos. Los ingenieros del S. XIX no negaron la estética, pero no la reconocieron como principio superior y determinante. Ella debía manifestarse en la cosa misma." (id:48)

Esta alusión a la "cosa misma" plantea el problema de la operación sobre lo real; siendo lugar para la aparición de una nueva dicotomización: Teoría y práctica. "Hoy es el proyectar mismo el que abre perspectivas. El solo, y no el espíritu de la época. El propio proyecto muestra lo que le ha acontecido, lo que es la cosa. Las respuestas ya no se hallan en el plano del espíritu, aunque sea el espíritu de la época, sino en la cosas. El mismo pan debe decir si aún puede comerse, la misma agua si aún puede beberse, el aire mismo si aún puede respirarse. El espíritu de la época es demasiado general".

El tema de la apariencia de la cosa misma, surgiendo como resultado de la aplicación de una metodología proyectual en la cual la forma sea tan evidente que hable por sí misma: "No se conforma con ser sólo apariencia" , dice Aicher, "la envoltura es la mentira", agrega. (id:57)

Por supuesto, debemos anclar espacial y temporalmente el texto para no tergiversar su sentido. Espacialmente Aicher habla desde, en y para Europa; aunque su mensaje se expande más allá del territorio supuesto por el enunciador. Sin embargo, conserva un rasgo diferenciador de la Modernidad, su pretensión de universalidad. Temporalmente: La postmodernidad. Esto es sumamente relevante, porque toda la rescritura del Diseño está atravesada por el deseo de Aicher de refundar el concepto esencial de lo proyectual en aquellos valores que están siendo nuevamente marginalizados por esa -nueva- corriente con pretensión de asumir el gobierno del imaginario del Diseño: "El centro Pompidou o el Hong Kong and Shangai Bank de Hong Kong trasladan a la arquitectura la técnica de la construcción de puentes.
Ello abre nuevos campos a la actividad del arquitecto, que ahora es libre de desprenderse de las cadenas formales del cuadrado, el círculo y el triángulo, libre para cumplir programas formales." (id:57)

Toda la puesta en discurso es un movimiento constante por expandir los límites del Diseño; definir su esencia por fuera de los estrechos márgenes de los procesos de formalización provenientes del arte. Una constante toma de partido, asunción de posición, lugar de quien habla; recolocación incesante de la mirada.

Sin embargo, lo que quiero hacer notar es la manera en que la rescritura de Aicher temporaliza los acontecimientos en función de construir un sentido: El pasado toma sentido en tanto se integra -junto con otros hechos- en una estructura que los ordena según el programa del sujeto que narra y que no es sino el despliegue de su intencionalidad hacia un objeto-valor, que genera una serie de pro-tensiones a lo largo del enunciado hacia un futuro que desarrolla esos valores.

Si la subjetividad enunciante aparece en la estructura misma del discurso, la objetividad pretendida es manifiestamente expresada.

"Por eso, decir que el viejo constructivismo, que produjo una serie de importantes edificios, atendió menos a la construcción que al aspecto de la construcción, no implica ningún juicio histórico valorativo." (id:56); afirmación minuciosamente contradicha por el tono enunciativo del texto.

Lo interesante es que tal temporalización avanza siempre motorizado por lo uno o lo otro: Polos radicalizados, ninguna reunión es posible. La figura del sujeto diseñador, en este trazado del imaginario a partir de la puesta en territorio del Diseño, se encuentra ante la imposibilidad de fluir de un extremo a otro: Inmovilizada, fijada por la propia historia no le queda más que tomar partido.

Espacialmente, el campo disciplinar se amplia hasta abarcar el mundo.

Todo es Diseño. Todo hay que crearlo. Todo, la vida, la cotidianeidad, lo privado y lo público precisa de la fuerza, el espíritu, la responsabilidad de la forma cumplida, la intervención creadora." (id:56)

La creación, la creatividad: La fuerza diferenciadora del sujeto Diseñador responsable de: Todo. ¿No vuelve a aparecer -bajo este concepto de fuerza- ese rasgo de mesianismo característico de la Modernidad, corregida ahora por la reubicación de la jerarquía en la escala de valores? Al desarrollar su programa, Aicher busca convencernos para que asumamos -desde el lugar de diseñadores de todonuestro hacer desde el otro platillo de la balanza: La técnica, que nos hace más responsables ante el corpus social que el de artista, sujeto a la moda, lo efímero, lo banal, los voluntarismos y las adhesiones personales -sintetizado en la particularidad. Y su vozenunciadora nos moviliza, casi nos instiga a realizarlo. El texto es iluminador en tanto en su desarrollo resume, a través de su tópica y su interdiscursividad con otros textos de la modernidad, todos los rasgos que figurativizan el Diseño modalizando la creatividad. 


\section{Dicotomización ciencia - arte}

Los rasgos actúan en distintos niveles que se superponen, se imbrican, se entretejen, niveles a través de los cuales el texto establece un anclaje con su exterior, lo fenoménico, los otros campos del saber, las otras disciplinas, lo social, lo económico, lo político. La dicotomización entre ciencia -bajo la forma de técnica- y arte se coloca a nivel epistemológico ${ }^{5}$. Aunque marginalizada en el momento en que lo artístico fue claramente instituido como disvalor frente a la acción proyectual- esto es procesos de racionalización, control y verificación del diseñadortécnico-, se reactiva con la aparición de las nuevas tecnologías digitales.

El tema que revela esta dicotomía es el de teoría y praxis. En su ponencia sobre relación entre enseñanza del Diseño Gráfico y su práctica, Martín Solomon habla de los nuevos "diseñadores-técnicos" que aparecieron con la emergencia de los programas de edición digital, que pasaron a dominar momentáneamente el mercado porque "... tenían el conocimiento del que carecía la mayoría de los profesionales en actividad -se refiere a comienzos de 1990. Esto contradecía el orden establecido, según el cual se necesitaban muchos años de experiencia antes de ser considerado un experto. En esta época muchos diseñadores que pensaban que podían prescindir de esta tecnología dependían de esta nueva generación para que fuera sus manos electrónicas. (Solomon, 1997:11)

Desplazamiento de lo viejo por lo nuevo que implica un redimensionamiento de la figura del diseñador en tanto poseedor de un saber-hacer. Lo interesante es que Solomon replantea los términos de la oposición sujeto-técnica -esto es control de los mecanismos de producción- desde una valoración ética, "amo o esclavo" se titula el artículo, produciendo una fuerte axiologización de los términos. A diferencia del texto de Aicher -donde este dilema no se plantea ya que la técnica no puede enfrentarse al sujeto porque es invocada como un co-sujeto en su función de herramienta- en el enunciado de Solomon, aunque reconoce su deuda de origen al afirmar "en ciertos sentidos -el Diseño- surge de la tecnología" (Solomon,1997:11), la tecnología -máquina, desplazada de su función de herramienta por las nuevas máquinas que simulan procesos racionales, puede conflictuar el lugar del sujeto al convertirse en su competidora: La tecnología ya no es transparente, ni puede ser sometida completamente a la voluntad del diseñador con tal de poseer su saberhacer. Solomon advierte que puede convertirse en un anti-sujeto, que lo lleve a perder su identidad. La tecnología es a la vez un valor positivo y un peligro: "Creo asimismo que la creatividad se ha visto beneficiada, por cuanto ha permitido a los diseñadores tomar conciencia de la amplitud de sus visiones conceptuales" (...) "La maldición de esta bendición fue que la tecnología abrió las compuertas y permitió el acceso a la industria de las comunicaciones a muchas personas con una preparación deficiente, que esgrimían el título genérico de 'diseñador'.
Muchos de estos advenedizos eran profesionales recién recibidos y estudiantes que trabajaban por su cuenta. Este dilema no se circunscribe a los primeros años de la tecnología, pues a medida que va apareciendo nueva tecnología el ciclo continua." (Solomon,1997:11)

En el sinfín de lo siempre nuevo aparece un fantasma concreto: El reemplazo del diseñador por la nueva generación de máquinas capaces de simular procesos cercanos a la creación. Pero, ¿Pueden realmente crear las máquinas? ¿Cuál es todavía el factor diferencial del sujeto? ¿Qué puede retener como competencia -en el sentido de su saber-hacer? Una concepción de creatividad orientada a factores extraterritorialespragmáticos, la concepción del telos, el objetivo: "Los conceptos creativos de las artes de las comunicación, empero, requieren asimismo que una solución responda a factores prácticos [...] en conjunto estos factores determinarán, en última instancia, si una pieza gráfica o publicitaria tendrá éxito." (id:12) Tener éxito: Esto es, cumplir su función, dicotomía a desarrollar a continuación, muestra el grado de imbricación de los niveles.

Es interesante hacer notar que de la praxis - técnica hemos pasado al terreno del arte por un cambio en la designación profesional que recupera su antigua denominación: Artes de la comunicación; arte como disposición, virtud o habilidad para hacer algo.

¿Por qué ha ocurrido este desplazamiento? El deslizamiento puede interpretarse como la necesidad enfática de recuperar el rol del sujeto asociado a la creatividad y los procesos creativos, poner en relevancia su singularidad connotada por la referencia a lo artístico. Recurrir a la polarización original para resolver el conflicto: La reserva del arte es la reserva del sujeto en tanto activa la figura de genio -creador desde una momento de iluminación- en la acepción del romanticismo. En este momento de peligro, aparece una remanencia que se resiste a ser sometida completamente a la racionalidad, y es aquí donde el discurso trae a la superficie la dicotomización original para salvar al sujeto. Conflicto de metodo- logías: Frente a la opacidad de método de la ciencia-técnica, a la ostensión de sus procesos, la transpa-rencia de la producción artística que no revela procedimientos ni protocolos sino objetos creados. En torno a la creatividad el sujeto de discurso hace aparecer nuevamente su desgarro.

\section{Dicotomización artista - técnico}

La polarización anterior actúa directamente en la caracterización de los sujetos diseñadores como artistas o técnicos, en los cuales el primero suele estar caracterizado como disvalor. El texto de Aicher antes analizado construye su sentido sobre tal sistema axiológico.

El diseñador artista figurativiza un sujeto que concibe sus objetos como expresión de un yo personal, que pierde el contacto con los fines, los objetivos, en fin, todo aquello que contribuye a anclar los productos de diseños en un mundo de otros - los usuarios. También Solomon advierte este peligro: 
"El entusiasmo, combinado con la idea de que no existen límites tecnológicos, a menudo produce piezas que expresan el 'yo' del diseñador en lugar del objetivo del proyecto. Una de las fuerzas que sustentan el diseño autocomplaciente es la influencia de modas pasajeras, en particular, las más radicales." (id:12-13)

Un imaginario detrás, el autor, la firma del artista, el desplazamiento del valor desde el objeto al sujeto; otra dicotomía que trasvasa largamente el campo del Diseño, pero que es ineludible en tanto que la operación básica de la proyectación es la generación objetos. Solomon especifica en torno al diseño de tendencias: "La aplicación indiscriminada de una tendencia implica el sacrificio del pensamiento creativo en aras de un efecto superficial. Los efectos pertenecen al ámbito de la máquina. Ofrecen técnicas a los estudiantes pero son incapaces de diseñar. Aquí se pone a prueba la relación entre el concepto y la tecnología." (id:13)

El efecto de superficie opuesto a la creación por expresión de esencias:

"Frente al efectismo y la superficialidad que hoy caracterizan a la praxis del diseño, es necesario definir con claridad su concepto y regresar a su esencia: Todo diseño - gráfico- posee un fin comunicacional y funcional." (Zimmermann, 1997: 24)

La figura del diseñador artista, convocada y construida -apelada- desde el efectismo, la moda, lo efímero, lo pasajero, lo mutable; todos valores negativos desde uno de los extremos de las prácticas del diseño, aparece como lugar óptimo para producir la ideologización de las figuras de diseñadores, por ser tan permeable a seducir "estudiantes", futuros operadores que tomarán la posta en el campo disciplinar. Justamente, al evocar esta figura aparece fuertemente un imaginario ligado a una utopía recurrente de la sociedad entre diseñador y artista: La de la autonomización del Diseño de sus fines. Los lazos que definen su relación con la extraterritorialidad de lo real es percibida como limitación de la capacidad creadora. Este imaginario rescata la figura mítico del artista bohemio y su creatividad como ejercicio de libertad. El diseñador-artista es el que ejerce su para-sí eludiendo el para-otros del Diseño. Quizás sea éste un punto interesante para reflexionar sobre el porqué activar precisamente esta figura del artista, que proviene de las nociones del arte y la estética como campos relacionados con el gusto y la arbitrariedad, y no la del artista conciente de sus procesos creativos que aplica la razón -aunque no las inferencias lógicas- y la intuición para relacionar su yo con el mundo y operar sobre éste sin someterlo.

Debido a ser especialmente sensible en los temas relativos a la enseñanza, los discursos se vuelven más monolíticos en tanto atacan esta tendencia:

"No hay nada peor para un diseñador que disponer de absoluta libertad, porque entonces 'todo vale'. Para su tarea es imprescindible que se le indique la meta que se pretende conseguir mediante el diseño". (id:25) Las metas la señala la recolección de datos prove- nientes de lo fenoménico - real. Sin embargo, esta tendencia hacia lo objetivo elude la problematización del concepto de realidad demostrado por la semiótica y la filosofía en las últimas décadas.

La distopía del sujeto-artista es la figura del diseñador-técnico, como el lugar otro de enunciación -vinculado a los factores económicos- pragmáticos a los que está sometido el Diseño.

"Si observamos atentamente cada profesión, cada actividad laboral, notaremos que cada una configura un corpus identificable que asigna a cada sujeto ciertos rasgos comunes. Esto hace que las actividades humanas resulten (...) igualitarias respecto de su función social. Así un diseñador gana protagonismo si hay que construir una imagen con significación." (Fernández,1997:28)

\section{Dicotomización forma - función}

La función social del diseñador y el Diseño activa otro par dicotómico que se actualiza en dos niveles: Estético y social.

Par complejo porque pone en cuestión los procesos de formalización y la cuestión de la apariencia por una parte y los acuerdos sociales y el rol del diseñador por el otro.

La modernidad histórica buscó resolver la polarización poniendo una en función de otra. La forma sigue a la función, fue el lema que se erigió como un mito ante los procesos de conformación de los objetos. El problema de la modernidad radicaba en su visión simplificadora de la función que podía ser resumida como la finalidad a la que está destinada el objeto. La función es mostrada como una condición afirmativa, positiva y el diseñador se figura como el que posee el saber-hacer necesario para su resolución. La diferencia que delimita el campo del Diseño es -una vez más- la aplicación de la capacidad creativa en la redimensión de los problemas. Al volver a la esencia del Diseño, su básico elemental, Zimmermann define:

"Todo diseño debe estar configurado para ser adecuado al uso que se va a hacer de él". (...) "El diseñador no hace arte, diseña objetos bidimensionales o tridimensionales que serán utilizados por usuarios. Los usos varían según la clase o tipología de los objetos y las modalidades de su uso están determinadas por la finalidad que se quiere conseguir con esos objetos. Un diseño no debe ser nunca un objeto en sí mismo, sino siempre un objeto para un fin." (Zimmermann,1997:25)

El riesgo mayor de esta sumisión de la forma en los fines, es la adscripción a los discursos del poder: Lejos de ser una comunidad utópica, la función ligada a lo social necesita ser repreguntada desde su para otros, ya que el campo social es definitivamente un campo conflictivo. En términos del texto de Zimmermann: Quienes son los usuarios y cómo se establece la tipología de objetos y la modalidad de uso.

El tema de la función toma relevancia desde la creatividad al vincularla a la conciencia de estar operando, en verdad, desde una región simbólica, en la cual la creatividad del sujeto diseñador dialoga con 
los imaginarios sociales, afirmando unos y poniendo en crisis otros. Algunas afirmaciones de Gérard Paris Clavel rescatan este lazo:

"La enseñanza de las artes plásticas no comienza con la carrera de arte, está presente a nuestro alrededor en todo contexto urbano, la arquitectura, lo símbolos en la calle, la vestimenta, los objetos, la prensa, etcétera. Justamente, la enseñanza tiene que estudiar, criticar e inventar esas formas cotidianas, ser creadora de memoria." (Paris Clavel,1997:16)

\section{Dicotomización imagen - palabra}

Los modos de representación del saber también escindieron la unidad entre imagen y palabra, y durante distintas etapas de la historia una prevaleció sobre la otra. La imagen se supuso difícil de codificar, perteneciente al ámbito de lo privado; la capacidad de dibujar -es decir la capacidad de representar mediante imágenes en el imaginario colectivo- la habilidad de unos pocos. La palabra -por otra partesusceptible de transmisibilidad, puede ser enseñada y aprendida aún sin ninguna predisposición natural. La polarización llevó a particularizar en la palabra su capacidad para transmitir ideas generales: Conceptos. El entendimiento y la interpretación del mundo quedó así en manos del lenguaje verbal.

Pero una de las capacidades explícitas del diseñador es la de desplegar su conocimiento desde el pensamiento visual: La visualización, la conceptualización a través de imágenes y la reinterpretación del imaginario, su traducción en imágenes rompe con la jerarquización de la palabra - una cultura verbocentrista. El Diseño recupera la imagen socializada a través del signo. El diseñador actúa aquí como un sujeto -performador $^{6}$, porque su pensamiento -sus representaciones, las modelizaciones virtuales de los objetos

\footnotetext{
Notas

${ }^{1}$ Barthes, R. trabaja desde la figurativización de su tema de investigación a partir de un fantasma: "Un fantasma (lo que al menos yo llamo así): Un retorno de deseos, imágenes, que merodean, se buscan en nosotros, a veces toda una vida, y a menudo sólo cristalizan en una palabra". Este ensayo se propone seguir el mismo procedimiento fantasmático explorando el significante 'creatividad'. Como vivir juntos: notas de cursos y seminarios en el Collège de France, 1976-1977.

2003. Siglo XXI: Argentina. Pág. 48.

Mijail Bajtin es quien primero desarrolla el tema de la interdiscursividad de los enunciados. Cfr Estética de la creación verbal. 1976 M éxico: Siglo XXI.

3 Herman Parret desarrolla la dicotomización de ambos discursos en el origen dela cultura occidental y una posible

\section{Bibliografía}

- Aicher, Otl El mundo como proyecto. (1994) Barcelona: Gili.

- Bajtin Mijail Estética de la creación verbal. (1976) M éxico: Siglo XXI

- Barthes Roland Como vivir juntos: Notas de cursos y seminarios en el Collège de France, 1976-1977. (2003) Siglo XXI: Argentina.
}

- son pensamientos que devienen en actos.

Sin embargo, el accionar del diseñador es una con tinua puesta en crisis del estrato referencial del lenguaje, de su anclaje en una realidad contextual que se toma como fija y que no constituye más que un acuerdo. “La realidad está constantemente actualizada o realizada por la fuerza del pensamiento. Además de esto, la actividad sígnica (...) no existe fuera del decir acerca de lo que es la realidad, fuera de la formulación de las propiedades conocibles del objeto real." (Panet, 2000:28)

\section{Como imaginar al diseñador desde la creatividad}

El recorrido por los rasgos señala la necesidad de revisar el imaginario del diseñador desde una utopía que abandone posiciones esclerosadas, que sólo producen simplificaciones reduccionistas de una actividad que debe operar en un mundo que se piensa - cada vez más- desde un mayor grado de complejidad. Tal vez, una de las razones de los desajustes entre la pedagogía y las prácticas del diseño, sea la incapacidad de abandonar ciertos modelos epistemológicos que se han vuelto axiomáticos, en los enunciados que definen a la profesión.

Quizás entonces una de las vías posibles sea el pensar la creatividad como posible puesta en escena del fantasma de quien diseña, en función de sus deseos -vistos como una pathos del sujeto- esto es, una tensión afectiva hacia un objeto -, objeto de Diseño entendido producto de una encrucijada de saberes que no deben ser resueltos desde la disciplina. Esta hipótesis busca reparar de esta manera el desgarro original, asumiendo en quien diseña un sujeto de razón y un sujeto de pasión -ser individual y ser socialartista y planificador; cortando el o de las elecciones extremas.

homologación. Cfr. De la semiótica a la estética: enunciación, sensación, pasiones: Contar.s.d. Edi-cial: Argentina ${ }^{4}$ La semiótica narratológica fue desarrolla por la escuela de Greimas, Cfr. Greimas A. y Courtes J. Semiótica. Diccionario razonado de las ciencias del lenguaje. 1982. Madrid: Gredos.

${ }^{5}$ Para un desarrollo crítico de los dos tipos de razonamiento aplicados al diseño cfr. Calletti, Sergio: Imaginación, positivismo y actividad proyectual. Nov. 2003 Cuadernos del Centro de Estudios en Diseño y Comunicación [Ensayos] № 15 P. 25 a 33

${ }^{6}$ Performación: acto del habla que efectúa lo que enuncia en el momento de su enunciación. Decir es hacer:

Austin, J. (How to do things with words).

- Bürdek, Bernhard Diseño. Historia, teoría y práctica del diseño industrial. 1994. Barcelona: Gili.

- Fernández, S. Diseñar para cada cual. (1997) Tipográfica \#33. Año XI. Argentina. Pág. 28. Los textos comentados de Silvia Fernández, Ives Zimmermann, Martín Solomon y Gèrard Paris Clavel son ponencias realizadas durante dos días del mes de junio de 1997, 
con motivo de la celebración de los 10 años de la revista tipográfica. El tema convocante era: "La formación del diseñador y la práctica profesional."

- Paris Clavel, Paris: El diseño social. (1997) Tipográfica \#33. Año XI. Argentina. p. 16

- Parret, Herman De la semiótica a la estética: Enuncia- ción, sensación, pasiones: Contar. s.d. Edicial: Argentina Salomon, M.: Amo o esclavo. (1997) Tipográfica \#33. Año XI. Argentina. p. 11-12

- Zimmerman, I. El diseño y su función. (1997) Tipográfica \#33. Año XI. Argentina. p. 24 